\title{
Testicular Tumor of the Thecoma/Fibroma Group
}

National Cancer Institute

\section{Source}

National Cancer Institute. Testicular Tumor of the Thecoma/Fibroma Group. NCI

Thesaurus. Code C39949.

A group of rare, slow-growing stromal tumors that arise from the testis. This category includes thecoma and fibroma. 